\title{
Impact of a programme of mass mammography screening for breast cancer on socio-economic variation in survival: a population-based study
}

\author{
W. J. Louwman · L. V. van de Poll-Franse · \\ J. Fracheboud · J. A. Roukema $\cdot$ J. W. W. Coebergh
}

Received: 16 November 2006/ Accepted: 25 November 2006/Published online: 9 January 2007

(C) Springer Science+Business Media B.V. 2006

\begin{abstract}
Background After a systematic mass mammography breast cancer screening programme was implemented between 1991 and 1996 (attendance 80\%), we evaluated its impact on survival according to socioeconomic status (SES).

Methods We studied survival rates up to 1-1-2005 for all consecutive breast cancer patients aged 50-69 and diagnosed in the period 1983-2002 in the area of the Eindhoven Cancer Registry $(n=4939)$. Multivariate analyses were performed using Cox regression analysis. Results The proportion of breast cancer patients with a low SES decreased from $22 \%$ in $1983-1990$ to $14 \%$ in 1997-2002 when attendance was $85 \%$. The proportion of newly diagnosed patients with stage III or IV disease in 1997-2002 was only $10 \%$ compared to $14 \%$ in $1991-$ 1996 and $26 \%$ in $1983-1989(P<0.0001)$. Stage distribution improved for all socio-economic groups $(P=0.01)$. Survival was similar for all socio-economic
\end{abstract}

W. J. Louwman $(\bowtie) \cdot$ L. V. van de Poll-Franse .

J. W. W. Coebergh

Eindhoven Cancer Registry, Comprehensive Cancer Centre

South (IKZ), Eindhoven, P.O. Box 231, 5600 AE

Eindhoven, The Netherlands

e-mail: research@ikz.nl

J. Fracheboud · J. W. W. Coebergh

Department of Public Health, Erasmus University Medical

Center Rotterdam, Rotterdam, The Netherlands

\section{J. A. Roukema}

Department of Surgery, St. Elisabeth Hospital, Tilburg,

The Netherlands

\section{J. A. Roukema}

Department of Psychology and Health, Tilburg University,

Tilburg, The Netherlands groups in 1983-1990, but after the introduction of the screening programme women with low SES had lower age- and stage-adjusted survival rates (HR 2.0, 95\% CI: 1.3-3.0). Survival was better for patients diagnosed in 1997-2002 compared to 1983-1990 for all socioeconomic strata; it was substantially better for the high SES group (HR 0.36, 0.2-0.5) compared to the lowest SES (HR 0.77, 0.6-1.1).

Conclusion Although survival improved for women from each of the socio-economic strata, related to the high participation rate of the screening programme, women from lower socio-economic strata clearly benefited less from the breast cancer screening programme. That is also related to the higher prevalence of comorbidity and possibly suboptimal treatment.

Keywords Breast cancer - Socio-economic status . Mass screening · Survival

\section{Introduction}

Mammography screening aims at early detection of breast cancer so that adequate treatment will eventually lower breast cancer mortality. In a mass screening programme, it is therefore especially important to reach women who have the highest chance of being diagnosed with advanced stage or have the lowest survival rates.

Women from lower socio-economic strata are less likely to attend population screening programmes [1-4] and are also more likely to present with unfavourable stage at diagnosis, [1, 5, 6] although not all studies confirm this [7-9]. Lower breast cancer survival rates among the disadvantaged are usually 
attributed to advanced stage at presentation, but also to suboptimal access to adequate treatment. A recent population-based study in Switzerland found social class to be an independent prognostic factor [10].

The mass breast cancer screening programme was introduced in 1991 for women of 50-69 years and became fully implemented in 1996 in the south of the Netherlands covered by the population-based Eindhoven Cancer Registry, with a continuous high participation rate. Based on previous work [11] and a new postcode-based indicator of socio-economic status (SES) introduced by Statistics Netherlands [12] we were able to investigate survival according to SES for a sufficient period of time after introduction.

We studied whether survival according to SES was affected differentially by the implementation of the screening programme.

\section{Methods}

The Eindhoven Cancer Registry records data on all patients newly diagnosed with cancer in the southeastern part of the Netherlands, an area with now 2.4 million inhabitants (about $15 \%$ of the Dutch population) and only general hospitals. Trained registry personnel actively collect data on diagnosis, staging, and treatment from the medical records after notification by pathologists and medical registration offices.

In the area of the Eindhoven Cancer Registry, a biennial breast cancer screening programme for women aged 50-69 years was started in 1991 and fully implemented in 1996. The attendance rate was more than $80 \%$ [13].

For our analyses we included all patients age 50-69 years diagnosed in 1983-2002 with invasive breast cancer in the eastern part of the registration area (about 1 million inhabitants). This population has been followed-up for vital status up to 1-1-2005. Information on the vital status of all patients was obtained initially from the municipal registries and since 1998 from the Central Bureau for Genealogy. These registers provide virtually complete coverage of all deceased Dutch citizens.

An indicator of socioeconomic status was developed by Statistics Netherlands [12] being based on individual fiscal data from the year 2000 on the economic value of the home and household income and provided at aggregated level for each postal code (average of 17 households). Socioeconomic status was categorized according to quintiles ranging from 1 (low) to 5 (high), with a separate class for postal codes with a care-providing institution (such as a nursing home). This measure is assumed to be valid ten years before and after the basic year (2000), so for patients diagnosed before 1990 we used a measure which was also based on postal code of residence, but socio-economic status (five categories) was based on data from a marketing agency (self-reported occupation and education define 45 social classes, collapsed into a 5-level indicator based on average number of years of education), as described before [11]. We also used both SES indicators for the whole study period (1983-2002) to make sure any effect of diagnostic period was not attributable to the indicator we used.

We calculated distribution of age and stage of disease according to period of diagnosis.

Stage was categorized according to the TNM classification [14]. Patients with either positive lymph nodes or metastases were considered to have advanced disease.

Chi-square test was performed of changes in the distribution across the three diagnostic periods. $T$-tests were performed of differences between two groups.

Crude survival analyses were performed. The logrank test was used to evaluate significant differences between survival curves in univariate analyses. We used Cox regression models to compute multivariate rates. The proportional hazard assumption of the predictor was evaluated by applying Kaplan-Meier Curves. The predictor satisfied the assumption of proportionality as the graphs of the survival function versus the survival time resulted in graphs with parallel curves as did the graphs of the $\log (-\log$ (survival)) versus log of survival time. The independent prognostic effect of SES was investigated, adjusting for age and stage of disease, and stratified according to period of diagnosis (1983-1990, 1991-1996, 1997-2002). We also calculated the age and stage-adjusted effect of period of diagnosis stratified according to SES.

\section{Results}

Median age was similar for all three periods of diagnosis $(59,60$, and 59 years, respectively).

Patients diagnosed between 1997 and 2002 had a significantly more favourable stage at diagnosis than patients diagnosed in earlier periods $(P<0.0001)$ : the proportion diagnosed with stage I (tumour smaller than $2 \mathrm{~cm}$, no axillary lymph nodes involved) increased from $30 \%$ in $1983-1990$ to $41 \%$ in $1991-1996$ and $45 \%$ in more recent years (Table 1). The proportion with advanced disease, i.e. stage III or IV, was significantly lower in the most recent period $(9.7 \%)$ compared to 1991-1996 (14\%) and 1983-1989 (26\%, $P<0.0001)$. Treatment varied over time, with a large proportion 
Table 1 Characteristics of all women age 50-69 years diagnosed with invasive breast cancer between 1983-2002 in Southeastern Netherlands

\begin{tabular}{|c|c|c|c|c|c|c|c|c|}
\hline & \multicolumn{2}{|c|}{ 1983-1990 } & \multicolumn{2}{|c|}{ 1991-1996 } & \multicolumn{2}{|c|}{ 1997-2002 } & \multicolumn{2}{|l|}{ Total } \\
\hline & $n$ & $\%$ & $n$ & $\%$ & $n$ & $\%$ & $n$ & $\%$ \\
\hline \multicolumn{9}{|l|}{ TNM } \\
\hline I & 465 & 30 & 642 & 41 & 838 & 45 & 1,945 & 39 \\
\hline II & 638 & 42 & 665 & 43 & 805 & 44 & 2,108 & 43 \\
\hline III & 278 & 18 & 152 & 10 & 115 & 6.2 & 545 & 11 \\
\hline IV & 115 & 7.5 & 68 & 4.4 & 65 & 3.5 & 248 & 5.0 \\
\hline unknown & 38 & 2.5 & 31 & 2.0 & 24 & 1.3 & 93 & 1.9 \\
\hline \multicolumn{9}{|l|}{ Treatment* } \\
\hline $\mathrm{S}$ alone & 271 & 18 & 341 & 22 & 249 & 13 & 861 & 17 \\
\hline $\mathrm{S}+\mathrm{RT}$ & 766 & 50 & 628 & 40 & 658 & 36 & 2,052 & 42 \\
\hline $\mathrm{S}+\mathrm{RT}+\mathrm{ST}$ & 305 & 20 & 422 & 27 & 673 & 36 & 1,400 & 28 \\
\hline $\mathrm{S}+\mathrm{ST}$ & 108 & 7 & 123 & 8 & 231 & 13 & 462 & 9.4 \\
\hline ST alone & 26 & 1.7 & 23 & 1.5 & 23 & 1.3 & 72 & 1.5 \\
\hline Other & 58 & 3.8 & 21 & 1.4 & 13 & 0.7 & 92 & 1.9 \\
\hline \multicolumn{9}{|c|}{ Socio-economic status } \\
\hline 1 (low) & 336 & 22 & 285 & 18 & 262 & 14 & 883 & 18 \\
\hline 2 & 325 & 21 & 319 & 20 & 342 & 19 & 986 & 20 \\
\hline 3 & 308 & 20 & 279 & 18 & 355 & 19 & 942 & 19 \\
\hline 4 & 154 & 10 & 274 & 18 & 358 & 19 & 786 & 16 \\
\hline 5 (high) & 302 & 20 & 315 & 20 & 414 & 22 & 1,031 & 21 \\
\hline institution\# & 0 & 0.0 & 23 & 1.5 & 33 & 1.8 & 56 & 1.1 \\
\hline unknown & 109 & 7.1 & 63 & 4.0 & 83 & 4.5 & 255 & 5.2 \\
\hline Total & 1,534 & & 1,558 & & 1,847 & & 4,939 & 100 \\
\hline
\end{tabular}

* S = Surgery, RT = Radiotherapy, ST = Systemic therapy

\#institution = care-providing institution such as a nursing home

receiving systemic therapy in recent years $(50 \%$, vs. $36 \%$ and $29 \%$ ).

The proportion of patients from the lowest socioeconomic class decreased from $22 \%$ in $1983-1990$ to $18 \%$ in $1991-1996$ and $14 \%$ in $1997-2002(P<0.0001)$, whereas the proportion from in the higher social classes increased.

Stage distribution improved significantly over time for each social class $(P<0.01)$. It was similar for all SES groups in 1983-1990 $(P=0.7$, Fig. 1$)$, although the proportion with stage IV was somewhat lower in the highest classes. The stage distribution was marginally more favourable for high SES compared to the lowest SES group in both 1991-1996 and 1997-2002 ( $P=0.06$ both periods), although the overall effect of SES on stage was not significant in the last period of time $(P=0.4)$.

Survival improved for all socio-economic strata over time (Fig. 2). Survival rates did not differ among patients from each of the socio-economic classes
Fig. 1 Stage distribution according to socio-economic status and period of diagnosis of patients age 50-69 years with invasive breast cancer in Southeastern Netherlands

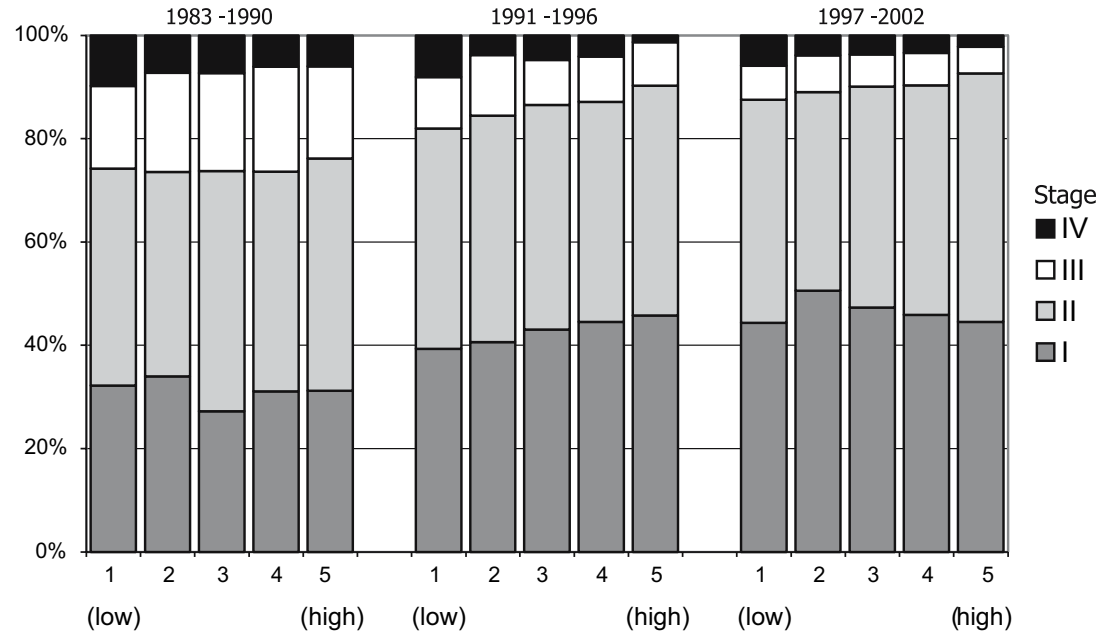


Fig. 2 Trend in survival according to socio-economic status for all women age 5069 years diagnosed with invasive breast cancer in Southeastern Netherlands
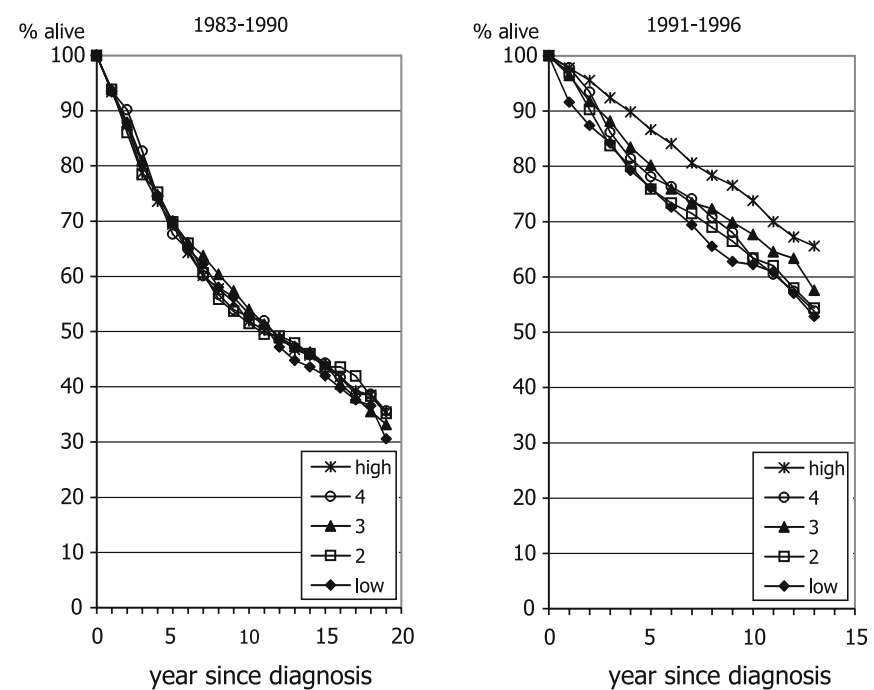

diagnosed 1983-1990 in the period $(P=0.9)$, 5-year survival rates being $70 \%, 70 \%, 70 \%, 68 \%$ and $69 \%$ for patients from the lowest to the highest social class, respectively. For patients diagnosed in 1991-1996, survival of patients with a high SES was better than that of all other socio-economic strata $(P=0.01)$, 5 -year survival rates being $76 \%, 76 \%, 80 \%, 78 \%$, and $87 \%$, respectively. For patients diagnosed in 1997-2002 an increasing gradient in survival was observed $(P=0.002)$ ranging from the lowest rates for the lowest SES group to the highest for the higher classes $(80 \%, 84 \%, 83 \%, 85 \%$, and $89 \%$, respectively).

Multivariate analysis (Table 2) showed that patients diagnosed between 1991 and 1996 from the lower social classes had a $29 \%$ higher risk of death compared to the highest socio-economic group, after adjusting for age and stage at diagnosis (HR for the lowest versus the highest SES group: $1.29,95 \%$ CI: $1.0-1.7)$. The risk of death for low SES patients diagnosed since 1997 was twice as high as that for the highest SES group (HR: 2.01, 95\% CI: 1.3-3.0). The overall effect of socio-economic status was significant in the last period $(P=0.02)$. Additional adjustment for treatment did not change risk estimates more than 5\% (data not shown).

Age and stage-adjusted survival improved over time for all socioeconomic strata (Table 3), the largest improvements were found for the highest social classes.

Table 2 Multivariate regression analysis of survival of breast cancer patients age 50-69 years according to period of diagnosis, Southeastern Netherlands

\begin{tabular}{|c|c|c|c|c|c|c|}
\hline & \multicolumn{2}{|c|}{ 1983-1990 } & \multicolumn{2}{|c|}{ 1991-1996 } & \multicolumn{2}{|c|}{ 1997-2002 } \\
\hline & $\mathrm{HR}^{* \mathrm{a}}$ & $95 \% \mathrm{CI}$ & $\mathrm{HR}^{* \mathrm{a}}$ & $95 \% \mathrm{CI}$ & $\mathrm{HR}^{* \mathrm{a}}$ & $95 \% \mathrm{Cl}$ \\
\hline Age (continuous) & 1.03 & $1.0-1.0$ & 1.04 & $1.0-1.1$ & 1.01 & $1.0-1.0$ \\
\hline \multicolumn{7}{|l|}{ Socio-economic status } \\
\hline 1 (low) & 1.01 & $0.8-1.2$ & 1.29 & $1.0-1.7$ & 2.01 & $1.3-3.0$ \\
\hline 2 & 1.03 & $0.8-1.3$ & 1.28 & $1.0-1.7$ & 1.54 & $1.0-2.3$ \\
\hline 3 & 0.95 & $0.8-1.2$ & 1.18 & $0.9-1.6$ & 1.53 & $1.0-2.3$ \\
\hline 4 & 0.99 & $0.8-1.3$ & 1.39 & $1.0-1.8$ & 1.33 & $0.9-2.0$ \\
\hline $5{\text { (high })^{\mathrm{b}}}$ & 1.00 & & 1.00 & & 1.00 & \\
\hline $\mathrm{X}^{2}$ trend & \multicolumn{2}{|c|}{$0.58(P=0.97)$} & \multicolumn{2}{|c|}{$5.9(P=0.21)$} & \multicolumn{2}{|c|}{$11.4(P=0.02)$} \\
\hline \multicolumn{7}{|l|}{ TNM stage } \\
\hline $\mathrm{I}^{\mathrm{b}}$ & 1.00 & & 1.00 & & 1.00 & \\
\hline II & 1.75 & $1.5-2.1$ & 2.33 & $1.9-2.9$ & 2.00 & $1.4-2.8$ \\
\hline III & 3.11 & $2.5-3.8$ & 4.67 & $3.5-6.2$ & 5.39 & $3.6-8.1$ \\
\hline IV & 9.85 & $7.6-13$ & 16.0 & $12-22$ & 16.5 & $11-24$ \\
\hline unknown & 2.25 & $1.4-3.5$ & 2.56 & $1.4-4.6$ & 4.81 & $2.3-10$ \\
\hline
\end{tabular}

\footnotetext{
* $\mathrm{HR}=$ Hazard Ratio, $\mathrm{CI}=$ Confidence Interval

a Adjusted for all variables listed

b Reference
} 
Table 3 Multivariate regression analysis of survival according to socio-economic status (SES) of breast cancer patients age 50-69 years in Southeastern Netherlands

\begin{tabular}{|c|c|c|c|c|c|c|c|c|c|c|}
\hline \multirow[t]{2}{*}{ SES } & \multicolumn{2}{|c|}{1 (low) } & \multicolumn{2}{|l|}{2} & \multicolumn{2}{|l|}{3} & \multicolumn{2}{|l|}{4} & \multicolumn{2}{|c|}{5 (high) } \\
\hline & $\mathrm{HR}^{* \mathrm{a}}$ & $95 \% \mathrm{CI}$ & $\mathrm{HR}^{* \mathrm{a}}$ & $95 \% \mathrm{CI}$ & $\mathrm{HR}^{* \mathrm{a}}$ & $95 \% \mathrm{CI}$ & $\mathrm{HR}^{* \mathrm{a}}$ & $95 \% \mathrm{CI}$ & $\mathrm{HR}^{* \mathrm{a}}$ & $95 \% \mathrm{CI}$ \\
\hline \multicolumn{11}{|c|}{ Period of diagnosis } \\
\hline $1983-1990^{\mathrm{b}}$ & 1.00 & & 1.00 & & 1.00 & & 1.00 & & 1.00 & \\
\hline 1991-1996 & 0.87 & $0.7-1.1$ & 0.72 & $0.6-0.9$ & 0.80 & $0.6-1.0$ & 0.84 & $0.6-1.1$ & 0.60 & $0.5-0.8$ \\
\hline 1997-2002 & 0.77 & $0.6-1.1$ & 0.49 & $0.4-0.7$ & 0.61 & $0.4-0.8$ & 0.49 & $0.3-0.7$ & 0.36 & $0.2-0.5$ \\
\hline$X^{2}$ trend & \multicolumn{2}{|c|}{$3.21(P=0.21)$} & \multicolumn{2}{|c|}{$20.9(P<0.001)$} & \multicolumn{2}{|c|}{$9.2(P=0.01)$} & \multicolumn{2}{|c|}{$14.1(P<0.001)$} & \multicolumn{2}{|c|}{$35.6(P<0.001)$} \\
\hline
\end{tabular}

\section{Discussion}

We found that the proportion of breast cancer patients with a low SES has decreased since the introduction of a mass biennial mammography screening programme with high response rates. Although stage distribution improved for all socio-economic groups, the proportion with advanced disease decreased the most in the highest socio-economic group. In the 1980s survival was similar for all socio-economic groups, but since the introduction of screening the survival of women with a high SES has improved more than that for low socioeconomic classes, also after adjustment for age and stage.

We used an indicator of socio-economic status based on the postal code of a residential area. This aggregate covers a relatively small geographical area, and thus represents a reliable approximation of individual socioeconomic status. Furthermore, routinely collected income tax data (no questionnaires or interviews) have been found to provide reliable estimates of household income. Previous studies have proven that socio-economic differences based on neighbourhood data tend to reflect socio-economic differences well at the individual level [15-17]. Furthermore, this objective measure of SES is also applicable for older women (born before 1955), whose occupation or education does not always properly reflect their social class [18]. We also repeated the analyses comparing both SES indicators if they were applied for the whole study period (19832002) to ensure any that effect of diagnostic period was not attributable to the indicator we used, and it was not.

The lower proportion of patients with a low SES since the introduction of screening is not likely to reflect the higher attendance rate of women from a higher social class because of the very high participation rate, although this is not known according to social class. Studies from other countries have shown that
SES does play a role in participation in the screening programme, [2] sometimes [3] but not always [4] due to the costs of a screening mammogram. However, the costs for the mass screening programme in the Netherlands are completely covered by public funds. Furthermore, the mean attendance rate in the Netherlands has always been rather high (about 80\%), [13] and in our study area even higher than the national mean (85\% in 2005) [19].

Foreign-born women are more likely to be nonattenders in the Netherlands, [20] as well as in Sweden, [21] Australia, [3] and the US, [22] for a variety of reasons. However the incidence of breast cancer among these groups of migrants is relatively low in the Netherlands and the stage distribution is comparable to that of women born in the Netherlands [20]. So this is unlikely to have affected survival rates in our study.

A lower attendance rate of low social classes will result in more advanced disease stages at presentation [23]. Before the start of the mammography screening programme, we found that the stage distribution for breast cancers diagnosed in 1980-1989 was slightly more favourable for the highest socio-economic group [24]. We have now shown that this was also true after the introduction of screening, although the differences were small. In fact, we found that, although stage distribution became more favourable for all socio-economic groups, the proportion with advanced disease decreased less in the lower socio-economic group. This differential stage distribution was also described in a recent Danish study, [6] although our differences were smaller.

The variation in survival according to SES may also be related to differences in treatment, which depends on the disease stage and varies over time. The use of surgery and radiotherapy was similar across SES groups. However, we found that the administration of adjuvant chemotherapy varied across the social strata among stage II patients ( $8 \%$ of the lowest SES group 
versus $17 \%$ of the highest SES group, $P<0.001)$. Patients with a higher SES seem to have benefited more from the general trend towards more adjuvant chemotherapy independent of the disease stage. This may explain, at least in part, the diverging trend in survival rates.

Another explanation for differential survival could be socio-economic variations in lifestyle. Smoking has become relatively more prevalent among low SES groups [25, 26]. This may have had an adverse effect on survival due to a poor general health while undergoing breast cancer treatment or to smoking related diseases (such as chronic obstructive pulmonary diseases (COPD) or cardiovascular disease).

Also related to an unhealthy lifestyle is obesity, which has become an increasingly important problem in the last decade, $[27,28]$ especially among women from the lower social classes [29].

Serious concomitant diseases besides breast cancer also affect survival rates, [30] which may explain differences in survival if comorbidity occurs more frequently in low SES groups.

Since the Eindhoven Cancer Registry has recorded comorbidity for all newly diagnosed patients since 1993, we checked whether the prevalence varied across socioeconomic strata. Indeed, the proportion of patients with comorbidity was higher among those with a lower SES $(70 \%$ of patients in the lowest SES group had one or more concomitant conditions compared to $60 \%$ of the high SES group). In particular, the prevalence of diabetes and cardiovascular disease was highest in the low SES groups (diabetes in $10 \%$ with low SES and $4 \%$ with high SES, cardiovascular disease $7 \%$ and $4 \%$, respectively).

Several studies have reported increased survival rates after the introduction of breast cancer screening [31-35]. As far as we know, no studies describe a differential effect of the introduction of screening on survival rates for socio-economic strata. However, socioeconomic inequalities in mortality have been widening in recent decades in western European countries [36]. In fact, socio-economic differences in breast cancer mortality increased between 1983 and 1993 among women in Finland and Italy (Turin), but remained stable in Denmark and decreased somewhat in Norway where a mass screening programme was only introduced later [36, 37].

In conclusion, despite a very high participation rate women from lower socio-economic strata clearly benefited less from the introduction of the breast cancer screening programme than those with a lower SES, probably due to a higher prevalence of comorbidity and suboptimal treatment (for both the cancer and the concomitant disease).

\section{References}

1. Bradley CJ, Given CW, Roberts C (2001) Disparities in cancer diagnosis and survival. Cancer 91:178-188

2. Zackrisson S, Andersson I, Manjer J, Janzon L (2004) Nonattendance in breast cancer screening is associated with unfavourable socio-economic circumstances and advanced carcinoma. Int J Cancer 108:754-760

3. O'Byrne AM, Kavanagh AM, Ugoni A, Diver F (2000) Predictors of non-attendance for second round mammography in an Australian mammographic screening programme. J Med Screen 7:190-194

4. Olsson S, Andersson I, Karlberg I, Bjurstam N, Frodis E, Hakansson S (2000) Implementation of service screening with mammography in Sweden: from pilot study to nationwide programme. J Med Screen 7:14-18

5. Schrijvers CT, Mackenbach JP, Lutz JM, Quinn MJ, Coleman MP (1995) Deprivation, stage at diagnosis and cancer survival. Int J Cancer 63:324-329

6. Dalton SO, During M, Ross L, Carlsen K, Mortensen PB, Lynch J, Johansen C (2006) The relation between socioeconomic and demographic factors and tumour stage in women diagnosed with breast cancer in Denmark, 19831999. Br J Cancer 95:653-659

7. Brewster DH, Thomson CS, Hole DJ, Black RJ, Stroner PL, Gillis CR (2001) Relation between socioeconomic status and tumour stage in patients with breast, colorectal, ovarian, and lung cancer: results from four national, population based studies. Br Med J 322:830-831

8. Carnon AG, Ssemwogerere A, Lamont DW, Hole DJ, Mallon EA, George WD, Gillis GR (1994) Relation between socioeconomic deprivation and pathological prognostic factors in women with breast cancer. Br Med J 309:1054-1057

9. Liu MJ, Hawk H, Gershman ST, Smith SM, Karacek R, Woodford ML, Ayanian JZ (2005) The effects of a National Breast and Cervical Cancer Early Detection Program on social disparities in breast cancer diagnosis and treatment in Massachusetts. Cancer Causes Control 16:27-33

10. Bouchardy C, Verkooijen HM, Fioretta G (2006) Social class is an important and independent prognostic factor of breast cancer mortality. Int J Cancer 119:1145-1151

11. Schrijvers CT, Coebergh JW, van der Heijden LH, Mackenbach JP (1995) Socioeconomic variation in cancer survival in the southeastern Netherlands, 1980-1989. Cancer 75:2946-2953

12. van Duijn C, Keij I (2002) Sociaal-economische status indicator op postcode niveau. Maandstatistiek van de bevolking 50:32-35

13. Verbeek AL, Broeders MJ (2003) Evaluation of The Netherlands breast cancer screening programme. Ann Oncol 14:1203-1205

14. Sobin L, Wittekind C (1997) TNM classification of malignant tumors, 5th ed New York. Wiley, NY

15. Bos V, Kunst AE, Mackenbach JP, Nationale gegevens over sociaal-economische sterfteverschillen op basis van informatie over kleine geografische eenheden. Instituut Maatschappelijke Gezondheidszorg, Erasmus Universiteit, 2000

16. Bos V, Kunst AE, Mackenbach JP (2001) De omvang van sociaal-economische sterfteverschillen gemeten op 
buurtniveau: vergelijking met schattingen op basis van informatie op individueel niveau. In: Stronks K (ed) Sociaaleconomische gezondheidsverschillen: Van verklaren naar verkleinen, vol 5. Den Haag, Zon/MW 8-20

17. Smits J, Keij I, Westert G (2001) Effecten van sociaal-economische status van kleine, middelgrote en grote geografische eenheden op de sterfte. Mndstat bevolking 11:4-10

18. Berkman LF, Macintyre S (1997) The measurement of social class in health studies: old measures and new formulations. IARC Sci Publ:51-64

19. [Annual report 2005] in Dutch. Stichting Bevolkingsonderzoek Borstkanker Zuid, 2006

20. Visser O, van der Kooy K, van Peppen AM, Ory FG, van Leeuwen FE (2004) Breast cancer risk among first-generation migrants in the Netherlands. Br J Cancer 90:2135-2137

21. Lagerlund M, Maxwell AE, Bastani R, Thurfjell E, Ekbom A, Lambe M (2002) Sociodemographic predictors of nonattendance at invitational mammography screening-a population-based register study (Sweden). Cancer Causes Control 13:73-82

22. Rimer BK, Keintz MK, Kessler HB, Engstrom PF, Rosan JR (1989) Why women resist screening mammography: patientrelated barriers. Radiology 172:243-246

23. Adams J, White M, Forman D. Are there socioeconomic gradients in stage and grade of breast cancer at diagnosis? Cross sectional analysis of UK cancer registry data. Br Med J 2004

24. Schrijvers CT, Coebergh JW, van der Heijden LH, Mackenbach JP (1995) Socioeconomic status and breast cancer survival in the southeastern Netherlands, 1980-1989. Eur J Cancer 31A:1660-1664

25. Stronks K, van de Mheen HD, Looman CW, Mackenbach JP (1997) Cultural, material, and psychosocial correlates of the socioeconomic gradient in smoking behavior among adults. Prev Med 26:754-766

26. Lahelma E, Rahkonen O, Berg MA, Helakorp S, Prattala R, Puska P, Uutela A (1997) Changes in health status and health behavior among Finnish adults 1978-1993. Scand J Work Environ Health 23(3):85-90

27. Gast GC, Frenken FJ, van Leest LA, Wendel-Vos GC, Bemelmans WJ (2006) Intra-national variation in trends in overweight and leisure time physical activities in The Netherlands since 1980: stratification according to sex, age and urbanisation degree. Int J Obes (Lond), Equb ahead of print
28. Visscher TL, Kromhout D, Seidell JC (2002) Long-term and recent time trends in the prevalence of obesity among Dutch men and women. Int J Obes Relat Metab Disord 26:12181224

29. Hulshof KF, Brussaard JH, Kruizinga AG, Telman J, Lowik MR (2003) Socio-economic status, dietary intake and $10 \mathrm{y}$ trends: the Dutch National Food Consumption Survey. Eur J Clin Nutr 57:128-137

30. Louwman WJ, Janssen-Heijnen ML, Houterman S, Voogd AC, van der Sangen MJ, Nieuwenhuijzen GA, Coebergh JW (2005) Less extensive treatment and inferior prognosis for breast cancer patient with comorbidity: a population-based study. Eur J Cancer 41:779-785

31. Otto SJ, Fracheboud J, Looman CW, Broeders MJ, Boer R, Hendriks JH, Verbeek AL, de Koning HJ (2003) Initiation of population-based mammography screening in Dutch municipalities and effect on breast-cancer mortality: a systematic review. Lancet 361:1411-1417

32. Blanks RG, Moss SM, McGahan CE, Quinn MJ, Babb PJ (2000) Effect of NHS breast screening programme on mortality from breast cancer in England and Wales, 1990-8: comparison of observed with predicted mortality. Br Med J 321:665-669

33. Hakama M, Pukkala E, Heikkila M, Kallio M (1997) Effectiveness of the public health policy for breast cancer screening in Finland: population based cohort study. Br Med J 14:864-867

34. Barchielli A, Paci E (2001) Trends in breast cancer mortality, incidence, and survival, and mammographic screening in Tuscany, Italy. Cancer Causes Control 12:249-255

35. Duffy SW, Tabar L, Chen HH, Holmqvist M, Yen MF, Abdsalah S, Epstein B, Frodis E, Ljungberg E, HedborgMelander C, Sundbom A, Tholin M et al (2002) The impact of organized mammography service screening on breast carcinoma mortality in seven Swedish counties. Cancer 95:458-469

36. Mackenbach JP, Bos V, Andersen O, Cardano M, Costa G, Harding S, Reid A, Hemstrom O, Valkonen T, Kunst AE (2003) Widening socioeconomic inequalities in mortality in six Western European countries. Int J Epidemiol 32:830-837

37. Zahl PH, Strand BH, Maehlen J (2004) Incidence of breast cancer in Norway and Sweden during introduction of nationwide screening: prospective cohort study. Br Med J 328:921-924 